\title{
Seroprevalence and Predictors of Hepatitis B Virus Infection among Pregnant Women Attending Routine Antenatal Care in Arba Minch Hospital, South Ethiopia
}

\author{
Tsegaye Yohanes, ${ }^{1}$ Zerihun Zerdo, ${ }^{1}$ and Nega Chufamo ${ }^{2}$ \\ ${ }^{1}$ Department of Medical Laboratory Science, Arba Minch University, P.O. Box 21, Arba Minch, Ethiopia \\ ${ }^{2}$ School of Medicine, Department of Obstetrics and Gynecology, Arba Minch University, P.O. Box 21, Arba Minch, Ethiopia \\ Correspondence should be addressed to Tsegaye Yohanes; tsegaye.yohanes@yahoo.com
}

Received 21 August 2015; Revised 3 November 2015; Accepted 9 November 2015

Academic Editor: Man-Fung Yuen

Copyright ( $) 2016$ Tsegaye Yohanes et al. This is an open access article distributed under the Creative Commons Attribution License, which permits unrestricted use, distribution, and reproduction in any medium, provided the original work is properly cited.

\begin{abstract}
Hepatitis B virus (HBV) is a serious cause of liver disease affecting millions of people throughout the world. When HBV is acquired during pregnancy, prenatal transmission can occur to the fetus. Therefore, this study is aimed at estimating seroprevalence and associated factors of HBV infection among pregnant women attending Antenatal Clinic (ANC) of Arba Minch Hospital, Southern Ethiopia. A facility based cross-sectional study was conducted on 232 pregnant women visiting ANC from February to April, 2015. Data regarding sociodemographic and associated factors were gathered using questionnaire. Serum samples were tested for hepatitis B surface antigen (HBsAg) by Enzyme Linked Immunosorbent Assay. Data was analyzed using SPSS version 20. The overall seroprevalence of HBV infection was 4.3\% (95\% CI: 2.2-6.9\%). Multivariate analysis showed that history of abortion $(\mathrm{AOR}=7.775$; 95\% CI: 1.538-39.301) and having multiple sexual partners (AOR $=7.189 ; 95 \%$ CI: 1.039-49.755) were independent predictors of HBsAg seropositivity. In conclusion, the prevalence of HBV infection is intermediate. Therefore, screening HBV infection should be routine part of ANC; health information on having single sexual partner for women of childbearing age and on following aseptic techniques during abortion should be provided to health facilities working on abortion.
\end{abstract}

\section{Introduction}

Hepatitis B virus is a potentially life-threatening cause of liver disease in the world. It both causes chronic infection and puts people at high risk of death from cirrhosis and liver cancer [1]. Globally, it is estimated that more than 2 billion people are still living with HBV infection. Over 350 million are believed to be chronically infected with the virus and are thought to be at a high risk of developing chronic hepatitis, cirrhosis, and primary hepatocellular carcinoma. About 1.2 million die annually from chronic hepatitis, cirrhosis, and hepatocellular carcinoma $[2,3]$.

Viral hepatitis during pregnancy is associated with high risk of maternal complications and high rate of vertical transmission. Fetal and neonatal hepatitis acquired from mother during pregnancy lead to impaired cognitive and physical development in latter life of the children [4]. The risk of vertical transmission depends on the time at which pregnant woman acquired HBV infection and on her statuses of $\mathrm{HBsAg}$ and hepatitis B early antigen ( $\mathrm{HBeAg}$ ) [5]. In the absence of immunoprophylaxis $10-20 \%$ of women seropositive for HBsAg transmit the virus to their neonates. Vertical transmission rate reaches approximately $90 \%$ when women are seropositive for both $\mathrm{HBsAg}$ and $\mathrm{HBeAg}$ [6].

The prevalence of chronic HBV infection is categorized as high $(\geq 8 \%)$, intermediate $(2-7 \%)$, and low $(<2 \%)$ [7]. In developed countries, the incidence of hepatitis is around $0.1 \%$ whereas in developing countries it ranges from 3 to $20 \%$ and even higher in some areas [8]. In Africa and Asia, the prevalence of $\mathrm{HBV}$ is $>8 \%$ and 2 billion people have markers of current or past infection with HBV [9]. About half of new infections result from vertical transmission during pregnancy, a statistic that is linked to the fact that HBV screening is not part of routine antenatal care in the area [10]. 
Immunization is estimated to avert between 2 and 3 million deaths globally each year. In Ethiopia, routine immunization was launched in 1980. Ethiopia has successfully introduced hepatitis B vaccine in the form of pentavalent combination vaccine into the routine schedule in 2007. Children under the age of one year are the target group for the vaccination [11]. There is no widely available treatment for chronic hepatitis B and the other sequelae of HBV infection in the country, and if they are available, this treatment cost falls on the individual patient $[12,13]$.

In Ethiopia, the prevalence of liver disease is high and accounts for $12 \%$ of the hospital admissions and $31 \%$ of mortality rate [14]. The prevalence of $\mathrm{HBV}$ infection among pregnant mothers in Addis Ababa was 7\% and 50\% had evidence of infection at the age of 20 years [15]. In similar studies conducted among pregnant women in Jimma, the prevalence of $\mathrm{HBV}$ infection was 3.7\% [16] while it was $4.9 \%$ and $8.1 \%$ among pregnant women in Dessie and Mekelle, respectively $[17,18]$.

Several studies around the world recommended that pregnant women should be screened for hepatitis B before delivery, as this offers an opportunity to prevent another generation from being chronically infected by the virus. However, in Ethiopia laboratory diagnosis of $\mathrm{HBV}$ infection is not part of routine care in ANC of all health facilities. Moreover, there is little information concerning seroprevalence of $\mathrm{HBV}$ infection among pregnant women and the existing data indicate that it differ from region to region as indicated above. Therefore, the present study is aimed to estimate seroprevalence of HBV infection and to identify associated risk factors among pregnant women attending ANC in Arba Minch Hospital, South Ethiopia.

\section{Methods}

2.1. Study Setting and Periods. The study was conducted from February to April 2015 in Antenatal Clinic of Arba Minch Hospital, which is found in Arba Minch Town. Arba Minch is located 505 kilometers in the southern part of Addis Ababa. The town is located in an altitude of 1200-1300 meters above sea level, with average annual temperature of $29^{\circ} \mathrm{C}$. Arba Minch Hospital serves more than 2 million people in South Nations Nationalities and Peoples Regional State in Ethiopia.

2.2. Study Design and Sample Size. A facility based crosssectional study design was used to enroll 232 pregnant women attending ANC in Arba Minch General Hospital. The sample size was determined using single population proportion formula to estimate the prevalence of $\mathrm{HBV}$ infection and Toxoplasma gondii infection among pregnant mothers attending ANC in Arba Minch General Hospital (larger project). The sample size is calculated based on the following assumptions: prevalence of HBV [18] and T. gondii [19] infections as $8.1 \%$ and $83.6 \%$, respectively; $95 \%$ level of confidence; $5 \%$ margin of error. Finally, $10 \%$ of nonresponse rate was added to the calculated sample size. Accordingly the minimum calculated sample size for HBV and T. gondii infections was 126 and 232. Finally we took the larger sample size calculated $(n=232)$.
2.3. Study Population and Sampling Technique. The present study was conducted among pregnant women attending ANC in Arba Minch Hospital and mentally fit to respond the questions. Systematic sampling technique was used to recruit pregnant mothers in the study. A total of 696 pregnant women attended the ANC clinic during the past three months before study was initiated. This number was divided for the sample size to get the sample interval ( $k$ value) which is 3 . Therefore, every 3rd mother attending the clinic was enrolled in the study until the calculated sample size was achieved within three months of data collection.

2.4. Data Collection. A pretested and structured questionnaire was used to collect information on sociodemographic, risky sexual behavior, history of hospital admission, history of abortion, and contact with HBV infected individuals. The data was collected through face-to-face interview by using nurses working in the ANC clinic of the hospital. Following the interview, approximately $2 \mathrm{~mL}$ of venous blood was collected from each consenting study participant by experienced phlebotomist. The blood was processed according to the standard operating procedures. Briefly, serum was separated from red blood cells and stored at $-20^{\circ} \mathrm{C}$ prior to assay. Finally, the serum was tested for HBsAg using ELISA test kit (DIALAB) at Arba Minch National blood bank center laboratory, strictly following the manufacturer's instruction.

2.5. Data Analysis. After checking for completeness and consistency of the collected information, the data was entered into computer, cleaned, and analyzed using SPSS version 20.0 software package. Descriptive statistic was performed to describe demographic profile of the study participants. Bivariate and multivariate logistic regressions were used to assess the association between potential risk factors considered and HBV infection. Variables with $p$ value $<0.25$ by the bivariate analysis were entered into multivariate model. At multivariate logistic regression, $p$ value $<0.05$ was set as statistically significant for all variables.

2.6. Ethical Considerations. Ethical clearance was approved and obtained from Arba Minch University College of Medicine and Health Science Research Ethical Review Committee. Official permission was sought from Arba Minch Zonal Health Bureau and Arba Minch Hospital Administration. Moreover, written informed consent was obtained from all study participants prior to interview and blood collection. Confidentiality of the collected information and laboratory test results was maintained. Individual test results were communicated with the attending physician for further management of the cases.

\section{Results}

3.1. Sociodemographic Characteristics. A total of 232 pregnant women who had been attending Arba Minch Hospital ANC clinic from February 2015 to April 2015 were included in the study. The mean age of the participants was 25.98 years dominantly within the age range of 25-29 years and standard deviation (SD) was 4.49. Higher proportions of the 
subjects were married and urban dwellers. Majority of the participants were housewives and had studied up to primary level education (Table 1).

3.2. Seroprevalence and Associated Factors of HBV Infection. Of 232 pregnant women tested for HBsAg, 10 (4.3\%) were found to be seropositive, giving the overall prevalence of $4.3 \%$ (95\% CI: 2.2-6.9\%). Pregnant women of age group of 25-29 years comprised 101 (43.5\%) of the total study participants, of which 4 (4\%) were seropositive. HBsAg seropositivity was observed to be higher in first trimester (5.1\%) and the least in the second trimester $(4.0 \%)$ but this difference was not statistically significant $(p>0.05)$. Moreover, none of the sociodemographic factors was significantly associated with HBsAg seropositivity (Table 2).

Sixteen (6.9\%) of pregnant women attending ANC clinic had were reported to have history of blood transfusion and $2(12.5 \%)$ of them were seropositive. However, blood transfusion was not significantly associated $(p=0.605)$ with prevalence of $\mathrm{HBV}$ infection among pregnant women attending ANC clinic in Arba Minch General Hospital. About $219(94.4 \%)$ and $54(23.3 \%)$ pregnant women had the practice of ear piercing and abortion, respectively. The respective prevalence of $\mathrm{HBV}$ infection among pregnant women who pierced their ear and aborted previously was 3.7\% $(n=8)$ and $13 \%(n=7)$. The significant association was observed between HBV infection and women who aborted previously $(p=0.013)$. Fifty-seven $(24.6 \%)$ of the study participants had also a history of hospital admission and only $2(3.5 \%)$ of them were seropositive. Concerning respondents of previous history of contracting Sexually Transmitted Disease (STD), of 10 pregnant women who had the disease, $2(22.2 \%)$ were seropositive. The prevalence of HBsAg among women who suffered from STD was significantly higher than those who did not suffer from STD in univariate logistic regression $(p=0.020)$ but this association was not maintained after controlling the effect of confounding variables in multivariate logistic regression $(p=0.450)$. In this study, $12(5.2 \%)$ pregnant women had previous history of multiple sexual partners and $2(16.7 \%)$ of them were seropositive. Sexual practice with more than one individual significantly $(p=$ 0.046 ) increases the transmission of $\mathrm{HBV}$ among pregnant women attending ANC clinic (Table 2).

\section{Discussion}

The seroprevalence of HBsAg among pregnant women attending ANC clinic in Arba Minch General Hospital was 4.3\%. According to WHO classification, the prevalence of HBsAg was intermediate among pregnant mothers [20]. Unless preventive measures through vaccination are taken to tackle the risk of transmission, the unborn babies are at a higher risk of contracting HBV infection. The infection was significantly higher among pregnant mothers who had aborted previously and had history of sex with multiple sexual partners. Health facilities or organizations working on abortion of pregnancies play great role in the transmission of the virus which might be associated with using unsterile equipment during the abortion process. Moreover, unsafe
TABLE 1: Sociodemographic characteristics of pregnant women $(n=$ 232) attending Antenatal Clinic at Arba Minch Hospital, 2015.

\begin{tabular}{|c|c|c|}
\hline Sociodemographic characteristics & Count $N$ & Percentage \% \\
\hline \multicolumn{3}{|l|}{ Age } \\
\hline $15-19$ & 16 & $6.9 \%$ \\
\hline $20-24$ & 69 & $29.7 \%$ \\
\hline $25-29$ & 101 & $43.5 \%$ \\
\hline $30-34$ & 35 & $15.1 \%$ \\
\hline $35-39$ & 11 & $4.7 \%$ \\
\hline \multicolumn{3}{|l|}{ Residence } \\
\hline Urban & 214 & $92.2 \%$ \\
\hline Rural & 18 & $7.8 \%$ \\
\hline \multicolumn{3}{|l|}{ Marital status } \\
\hline Married & 224 & $96.6 \%$ \\
\hline Single & 6 & $2.6 \%$ \\
\hline Divorced & 0 & $0.0 \%$ \\
\hline Widowed & 2 & $0.9 \%$ \\
\hline \multicolumn{3}{|l|}{ Educational status } \\
\hline Unable to read and write & 47 & $20.3 \%$ \\
\hline Primary & 79 & $34.1 \%$ \\
\hline Secondary & 71 & $30.6 \%$ \\
\hline Tertiary & 35 & $15.1 \%$ \\
\hline \multicolumn{3}{|l|}{ Occupation } \\
\hline Government & 67 & $28.9 \%$ \\
\hline Housewife & 140 & $60.3 \%$ \\
\hline Others ${ }^{\diamond}$ & 25 & $10.8 \%$ \\
\hline \multicolumn{3}{|l|}{ Trimesters } \\
\hline First (<14 weeks) & 39 & $16.8 \%$ \\
\hline Second (14-28 weeks) & 124 & $53.4 \%$ \\
\hline Third (>28 weeks) & 69 & $29.7 \%$ \\
\hline \multicolumn{3}{|l|}{ Gravidity } \\
\hline Primigravidae & 85 & $36.6 \%$ \\
\hline Multigravidae & 147 & $63.4 \%$ \\
\hline
\end{tabular}

$\diamond$ includes students, merchants, and farmers.

sexual practice with multiple sexual partners is the major way of transmission of HBV among women of the childbearing age.

The prevalence of $\mathrm{HBsAg}$ among pregnant women attending ANC clinic in Arba Minch General Hospital was comparable with studies conducted in Bahir Dar (3.8\%) [21], Jimma (3.7\%) [16] and Dessie (4.9\%) [17], Dares Salaam in Tanzania (3.9\%) [22], and Lagos Nigeria (4.2\%) [23]. In contrast to our study, the highest prevalence was reported from Benin (12.5\%) [24], Cameron (10.2\%) [25], and Mali (8\%) [26]. On the other hand, the lowest prevalence was reported from two studies from India [27, 28]. The difference between the present studies and the above studies might be due to difference in socioeconomy and behavioral and cultural practices of age between 15 and 45 years.

In agreement with other studies $[29,30]$ HBsAg seropositivity was not significantly different by age. There was no difference in seropositivity of HBsAg between urban and rural pregnant mothers in the present study and it is in 
TABLE 2: Bivariate and multivariate analyses of factors associated with HBV infection in the study participants, Arba Minch Hospital, 2015.

\begin{tabular}{|c|c|c|c|c|c|c|}
\hline \multirow{2}{*}{ Variables } & \multicolumn{2}{|c|}{ Seroprevalence } & \multirow{2}{*}{ COR $(95 \% \mathrm{CI})$} & \multirow{2}{*}{$p$ value } & \multirow{2}{*}{$\operatorname{AOR}(95 \% \mathrm{CI})$} & \multirow{2}{*}{$p$ value } \\
\hline & Positive $n(\%)$ & Negative $n(\%)$ & & & & \\
\hline \multicolumn{7}{|l|}{ Age } \\
\hline $15-19$ & $1(6.2 \%)$ & $15(93.8 \%)$ & $1.617(0.169-15.458)$ & 0.677 & & \\
\hline $20-24$ & $3(4.3 \%)$ & $66(95.7 \%)$ & $1.102(0.239-5.087)$ & 0.901 & & \\
\hline $25-29$ & $4(4.0 \%)$ & $97(96.0 \%)$ & 1 & & & \\
\hline $30-34$ & $1(2.9 \%)$ & $34(97.1 \%)$ & $0.713(0.077-6.606)$ & 0.766 & & \\
\hline $35-39$ & $1(9.1 \%)$ & $10(90.9 \%)$ & $2.425(0.247-23.850)$ & 0.448 & & \\
\hline \multicolumn{7}{|l|}{ Residence } \\
\hline Urban & $9(4.2 \%)$ & $205(95.8 \%)$ & 1 & & & \\
\hline Rural & $1(5.6 \%)$ & $17(94.4 \%)$ & $1.340(0.160-11.212)$ & 0.787 & & \\
\hline \multicolumn{7}{|l|}{ Educational status } \\
\hline Unable to read and write & $2(4.3 \%)$ & $45(95.7 \%)$ & $0.833(0.147-4.734)$ & 0.837 & & \\
\hline Primary & $4(5.1 \%)$ & $75(94.9 \%)$ & 1 & & & \\
\hline Secondary & $2(2.8 \%)$ & $69(97.2 \%)$ & $0.543(0.096-3.061)$ & 0.489 & & \\
\hline Tertiary & $2(5.7 \%)$ & $33(94.3 \%)$ & $1.136(0.198-6.514)$ & 0.886 & & \\
\hline \multicolumn{7}{|l|}{ Occupation } \\
\hline Government & $2(3.0 \%)$ & $65(97.0 \%)$ & $0.585(0.118-2.893)$ & 0.511 & & \\
\hline Housewife & $7(5.0 \%)$ & $133(95.0 \%)$ & 1 & & & \\
\hline Others & $1(4.0 \%)$ & $24(96.0 \%)$ & $0.792(0.093-6.728)$ & 0.831 & & \\
\hline \multicolumn{7}{|l|}{ Trimesters } \\
\hline First (<14 weeks) & $2(5.1 \%)$ & $37(94.9 \%)$ & $1.286(0.240-6.908)$ & 0.769 & & \\
\hline Second (14-28 weeks) & $5(4.0 \%)$ & $119(96.0 \%)$ & 1 & & & \\
\hline Third (>28 weeks) & $3(4.3 \%)$ & $66(95.7 \%)$ & $1.082(0.251-4.670)$ & 0.916 & & \\
\hline \multicolumn{7}{|l|}{ Gravidity } \\
\hline Primigravidae & $4(4.7 \%)$ & $81(95.3 \%)$ & $1.160(0.318-4.234)$ & 0.822 & & \\
\hline Multigravidae & $6(4.1 \%)$ & $141(95.9 \%)$ & 1 & & & \\
\hline \multicolumn{7}{|l|}{ Blood transfusion } \\
\hline No & $8(3.7 \%)$ & $208(96.3 \%)$ & 1 & & 1 & \\
\hline Yes & $2(12.5 \%)$ & $14(87.5 \%)$ & $3.714(0.720-19.172)$ & $0.117^{\oplus}$ & $1.689(0.232-12.296)$ & 0.605 \\
\hline \multicolumn{7}{|l|}{ Ear piercing } \\
\hline No & $2(15.4 \%)$ & $11(84.6 \%)$ & 1 & & 1 & \\
\hline Yes & $8(3.7 \%)$ & $211(96.3 \%)$ & $0.209(0.039-1.101)$ & $0.065^{\oplus}$ & $0.220(0.022-2.161)$ & 0.194 \\
\hline \multicolumn{7}{|l|}{ Nose piercing } \\
\hline No & $9(4.1 \%)$ & $213(95.9 \%)$ & 1 & & & \\
\hline Yes & $1(10.0 \%)$ & $9(90.0 \%)$ & $2.630(0.300-23.054)$ & 0.383 & & \\
\hline \multicolumn{7}{|l|}{ Body tattooing } \\
\hline No & $8(3.7 \%)$ & $209(96.3 \%)$ & 1 & & 1 & \\
\hline Yes & $2(13.3 \%)$ & $13(86.7 \%)$ & $4.019(0.774-20.879)$ & $0.098^{\oplus}$ & $5.372(0.617-46.751)$ & 0.128 \\
\hline \multicolumn{7}{|l|}{ Tooth extraction } \\
\hline No & $8(4.5 \%)$ & $171(95.5 \%)$ & 1 & & & \\
\hline Yes & $2(3.8 \%)$ & $51(96.2 \%)$ & $0.838(0.173-4.073)$ & 0.827 & & \\
\hline \multicolumn{7}{|l|}{ Hospital admission } \\
\hline No & $8(4.6 \%)$ & $167(95.4 \%)$ & 1 & & & \\
\hline Yes & $2(3.5 \%)$ & $55(96.5 \%)$ & $0.759(0.156-3.682)$ & 0.732 & & \\
\hline \multicolumn{7}{|l|}{ History of surgery } \\
\hline No & $9(4.2 \%)$ & $204(95.8 \%)$ & 1 & & & \\
\hline Yes & $1(5.3 \%)$ & $18(94.7 \%)$ & $1.259(0.151-10.506)$ & 0.831 & & \\
\hline \multicolumn{7}{|c|}{ Contact with liver disease patient } \\
\hline No & $9(4.1 \%)$ & $211(95.9 \%)$ & 1 & & & \\
\hline Yes & $1(8.3 \%)$ & $11(91.7 \%)$ & $2.131(0.248-18.353)$ & 0.491 & & \\
\hline
\end{tabular}


TABLE 2: Continued.

\begin{tabular}{|c|c|c|c|c|c|c|}
\hline \multirow{2}{*}{ Variables } & \multicolumn{2}{|c|}{ Seroprevalence } & \multirow{2}{*}{ COR $(95 \%$ CI $)$} & \multirow{2}{*}{$p$ value } & \multirow{2}{*}{$\mathrm{AOR}(95 \% \mathrm{CI})$} & \multirow{2}{*}{$p$ value } \\
\hline & Positive $n(\%)$ & Negative $n(\%)$ & & & & \\
\hline \multicolumn{7}{|c|}{ History of abortion } \\
\hline No & $3(1.7 \%)$ & $175(98.3 \%)$ & 1 & & 1 & \\
\hline Yes & $7(13.0 \%)$ & $47(87.0 \%)$ & $8.688(2.163-34.891)$ & $0.002^{\oplus}$ & $7.775(1.538-39.301)$ & $0.013^{*}$ \\
\hline \multicolumn{7}{|c|}{ History of alcohol drinking } \\
\hline No & $7(3.6 \%)$ & $187(96.4 \%)$ & 1 & & 1 & \\
\hline Yes & $3(7.9 \%)$ & $35(92.1 \%)$ & $3.562(0.956-13.276)$ & $0.058^{\oplus}$ & $1.674(0.339-8.257)$ & 0.527 \\
\hline \multicolumn{7}{|c|}{ Delivery by TBA } \\
\hline No & $9(4.2 \%)$ & $204(95.8 \%)$ & 1 & & & \\
\hline Yes & $1(5.3 \%)$ & $18(94.7 \%)$ & $1.259(0.151-10.506)$ & 0.831 & & \\
\hline \multicolumn{7}{|c|}{ History of STD } \\
\hline No & $8(3.6 \%)$ & $215(96.4 \%)$ & 1 & & 1 & \\
\hline Yes & $2(22.2 \%)$ & $7(77.8 \%)$ & $7.679(1.371-42.995)$ & $0.020^{\oplus}$ & $2.430(0.243-24.295)$ & 0.450 \\
\hline \multicolumn{7}{|c|}{ Multiple sexual partners } \\
\hline No & $8(3.6 \%)$ & $212(96.4 \%)$ & 1 & & 1 & \\
\hline Yes & $2(16.7 \%)$ & $10(83.3 \%)$ & $5.300(0.993-28.275)$ & $0.051^{\oplus}$ & $7.189(1.039-49.755)$ & $0.046^{*}$ \\
\hline
\end{tabular}

${ }^{\oplus}$ Candidate variable for multivariate analysis at $p<0.25 ;{ }^{*}$ variable significant by the multivariate analysis at $p<0.05$. COR: crude odds ratio, AOR: adjusted odds ratio, CI: confidence interval, TBA: traditional birth attendant, and STD: Sexually Transmitted Disease.

agreement with a study reported from Sana'a, Yemen [30]. In contrast to our study, study from Eastern Sudan has shown significantly higher prevalence of HBsAg among pregnant mothers from urban area than the rural counterparts [31]. This difference might be due to the varied numbers of urban and rural study participants as compared to our study.

According to this study, the prevalence of HBsAg was significantly higher among pregnant women who had history of abortion. Unplanned pregnancy is related to unprotected sexual intercourse which results in abortion and also increases the risk of HBV infection if such partners are infected. Also, instrumentation during abortion and related activities may serve as sources of exposure; all these circumstances may increase the likelihood of acquiring the infection. This is in agreement with a study reported from Lagos Nigeria [23] but in contrast with similar study carried out in North West of Iran [32].

In the current study, the rate of HBV infection was significantly higher and about seven times more likely to occur in those who had history of multiple sexual partners as compared to those who did not have multiple sexual partners. The significant association of having multiple sexual partners with $\mathrm{HBV}$ infection was also documented by other investigators [18, 33]. In contrast, some studies have shown that there was no significant association between abortion and seropositivity of HBsAg among pregnant mothers [22, 34]. Hepatitis B virus infection is sexually transmitted and the transmission increases with the duration of sexual activity and number of sexual partners $[35,36]$.

Blood transfusion is one of the means of transmission of bloodborne pathogen like HBV but it was not significantly associated with HBsAg seropositivity in the present study. This finding corroborates the report from Nigeria [37]. However, blood transfusion was significantly associated with transmission of HBV in a number of studies [21, 23, 28]. Improving the quality of laboratory screening of blood for
$\mathrm{HBV}$ is one of the components in reducing the risk for transfusion-transmitted HBV. The possible explanation for absence of significant association between HBV infection and blood transfusion might be improved screening of $\mathrm{HBV}$ infection from blood donors before transfusion in Ethiopia.

The rate of vertical transmission of HBV infection is influenced by the time of pregnancy at which acute HBV infection occurs in the mothers [5]. In our study, the highest seroprevalence of $\mathrm{HBV}$ infection was found in those pregnant women at the first trimester as compared to second and third trimesters. However, there was no statistically significant difference in the prevalence of HBsAg seropositivity in different gestational age of pregnant mothers and it was in agreement with other studies $[29,38]$.

\section{Conclusions}

In conclusion, the prevalence of HBsAg among pregnant mothers attending ANC clinic in Arba Minch general hospital was intermediate. Abortion and unsafe sexual practice with more than one sexual partner play significant role in the transmission of the virus from infected person to healthy women of childbearing age. Therefore, screening pregnant women for HBV infection should be part of the routine care in ANC clinic in Arba Minch general hospital and in other similar settings. Health information on safe sex to women of childbearing age should be given to interrupt the transmission. In addition, health facilities working on abortion should strictly follow the aseptic techniques in order to save the life of both aborting mother and subsequent children of that mother.

\section{Conflict of Interests}

The authors declare that they do not have any conflict of interests. 


\section{Authors' Contribution}

Tsegaye Yohanes conceived the study, participated in the study design and data analysis, and drafted the paper. Zerihun Zerdo and Nega Chufamo participated in the study design, data acquisition, and data analysis. All authors contributed to the writing of the paper and approved the final paper.

\section{Acknowledgments}

The authors would like to thank staff members of Arba Minch Hospital ANC clinic for their cooperation during data collection. They are grateful to Arba Minch Blood Bank center staff for their cooperation. They are also grateful to the study participants. This research was financially supported by Arba Minch University.

\section{References}

[1] World Health Organization, "Hepatitis B," Fact Sheet 204, World Health Organization, Geneva, Switzerland, 2015, http://www.who.int/mediacentre/factsheets/fs204/en/.

[2] M. J. U. Dahoma, A. A. Salim, R. Abdool et al., "HIV and substance abuse: the dual epidemics challenging Zanzibar," African Journal of Drug \& Alcohol Studies, vol. 5, no. 2, pp. 131139, 2006.

[3] R. M. Merrill and B. D. Hunter, "Sero-prevalence of markers for hepatitis B viral infection," International Journal of Infectious Diseases, vol. 15, no. 2, pp. e78-e121, 2011.

[4] A. O. Olaitan and L. G. Zamani, "Prevalence of hepatitis B virus and hepatitis $\mathrm{C}$ virus in ante-natal patients in GwagwaladaAbuja, Nigeria," Report and Opinion, vol. 2, no. 7, pp. 48-50, 2010.

[5] N.-C. Vu Lam, P. B. Gotsch, and R. C. Langan, "Caring for pregnant women and newborns with hepatitis B or C," American Family Physician, vol. 82, no. 10, pp. 1225-1229, 2010.

[6] American College of Obstetricians and Gynecologists, "Viral hepatitis in pregnancy," Obstetrics \& Gynecology, vol. 110, no. 4, pp. 941-956, 2007, ACOG Practice Bulletin No. 86.

[7] Centers for Disease Control and Prevention, "Recommendations for identification and public health management of persons with chronic hepatitis B virus infection," Morbidity and Mortality Weekly Report, vol. 57, pp. 1-20, 2008.

[8] S. Shukla, G. Mehta, M. Jais et al., "A prospective study on acute viral hepatitis in pregnancy; seroprevalence, and fetomaternal outcome of 100 cases," Journal of Bioscience and Technology, vol. 2, no. 3, pp. 279-286, 2011.

[9] N. Leung, "Chronic hepatitis B in Asian women of childbearing age," Hepatology International, vol. 3, supplement 1, pp. 24-31, 2009.

[10] MCHP-Maternal and Child Health Integrated Program, "Intersecting Epidemics: An Overview of the Causes of Maternal Death and Infectious Diseases," 2014, http:// www.mchip.net/sites/default/files/Maternal\%20Health_Infectious\%20Diseases\%20Overview\%20Briefer.pdf.

[11] FMOH, National Expanded Programme on Immunization Comprehensive Multi-Year Plan 2011-2015, Federal Ministry of Health, Addis Ababa, Ethiopia, 2010.

[12] A. Bane, A. Patil, and M. Khatib, "Healthcare cost and access to care for viral hepatitis in Ethiopia," International Journal of Innovation and Applied Studies, vol. 9, no. 4, pp. 1718-1723, 2014.
[13] W. J. Edmunds, A. Dejene, Y. Mekonnen, M. Haile, W. Alemnu, and D. J. Nokes, "The cost of integrating hepatitis B virus vaccine into national immunization programmes: a case study from Addis Ababa," Health Policy and Planning, vol. 15, no. 4, pp. 408-416, 2000.

[14] E. Tsega, "Epidemiology, prevention and treatment of viral hepatitis with emphasis on new developments," Ethiopian Medical Journal, vol. 38, no. 2, pp. 131-141, 2000.

[15] A. Abebe, D. J. Nokes, A. Dejene, F. Enquselassie, T. Messele, and F. T. Cutts, "Seroepidemiology of hepatitis B virus in Addis Ababa, Ethiopia: transmission patterns and vaccine control," Epidemiology and Infection, vol. 131, no. 1, pp. 757-770, 2003.

[16] M. Awole and S. Gebre-Selassie, "Seroprevalence of HBsAg and its risk factors among pregnant women in Jimma, Southwest Ethiopia," Ethiopian Journal of Health Development, vol. 19, no. 1, pp. 45-50, 2005.

[17] M. Seid, B. Gelaw, and A. Assefa, "Sero-prevalence of HBV and $\mathrm{HCV}$ infections among pregnant women attending antenatal care clinic at Dessie Referral Hospital, Ethiopia," Advances in Life Sciences and Health, vol. 1, no. 2, pp. 109-120, 2014.

[18] A. Semaw, H. Awet, and M. Yohannes, "Sero-prevalence of hepatitis B surface antigen and associated factors among pregnant mothers attending antenatal care service, Mekelle, Ethiopia: evidence from institutional based quantitative cross-sectional study," World Academy of Science, Engineering and Technology: Medical and Health Sciences, vol. 2, no. 9, 2015.

[19] E. Zemene, D. Yewhalaw, S. Abera, T. Belay, A. Samuel, and A. Zeynudin, "Seroprevalence of Toxoplasma gondii and associated risk factors among pregnant women in Jimma town, Southwestern Ethiopia," BMC Infectious Diseases, vol. 12, article 337, 2012.

[20] WHO/EPI, "Protocol for assessing prevalence of hepatitis B infection in antenatal patients," Tech. Rep. WHO/EPI/GEN/ 90.6, World Health Organization, Geneva, Switzerland, 1990, http://www.who.int/iris/handle/10665/61617.

[21] Y. Zenebe, W. Mulu, M. Yimer, and B. Abera, "Sero-prevalence and risk factors of hepatitis B virus and human immunodeficiency virus infection among pregnant women in Bahir Dar city, Northwest Ethiopia: a cross sectional study," BMC Infectious Diseases, vol. 14, no. 1, article 118, 2014.

[22] S. Rashid, C. Kilewo, and S. Aboud, "Seroprevalence of hepatitis $\mathrm{B}$ virus infection among antenatal clinic attendees at a tertiary hospital in Dar es Salaam, Tanzania," Tanzania Journal of Health Research, vol. 1, no. 16, pp. 1-8, 2014.

[23] O. C. Ezechi, O. O. Kalejaiye, C. V. Gab-Okafor et al., "Seroprevalence and factors associated with Hepatitis B and C co-infection in pregnant Nigerian women living with HIV Infection," The Pan African Medical Journal, vol. 17, article 197, 2014.

[24] O. Ugbebor, M. Aigbirior, F. Osazuwa, E. Enabudoso, and O. Zabayo, "The prevalence of hepatitis B and $\mathrm{C}$ viral infections among pregnant women," North American Journal of Medical Sciences, vol. 3, no. 5, pp. 238-241, 2011.

[25] J. J. Noubiap, J. R. Nansseu, S. T. Ndoula, J. J. Bigna, A. M. Jingi, and J. Fokom-Domgue, "Prevalence, infectivity and correlates of hepatitis B virus infection among pregnant women in a rural district of the Far North Region of Cameroon," BMC Public Health, vol. 15, article 454, 2015.

[26] B. MacLean, R. F. Hess, E. Bonvillain et al., "Seroprevalence of hepatitis B surface antigen among pregnant women attending the hospital for women \& children in Koutiala, Mali," South African Medical Journal, vol. 102, no. 1, pp. 47-49, 2012. 
[27] K. S. Saraswathi and F. Aljabri, "The study of prevalence of Hepatitis B surface antigen during pregnancy in a tertiary care hospital, South India," Der Pharmacia Lettre, vol. 4, no. 3, pp. 983-985, 2012.

[28] C. Pande, S. K. Sarin, S. Patra et al., "Prevalence, risk factors and virological profile of chronic hepatitis b virus infection in pregnant women in India," Journal of Medical Virology, vol. 83, no. 6, pp. 962-967, 2011.

[29] O. M. Kolawole, A. A. Wahab, D. A. Adekanle, T. Sibanda, and A. I. Okoh, "Seroprevalence of hepatitis B surface antigenemia and its effects on hematological parameters in pregnant women in Osogbo, Nigeria," Virology Journal, vol. 9, article 317, 2012.

[30] E. A. Murad, S. M. Babiker, G. I. Gasim, D. A. Rayis, and I. Adam, "Epidemiology of hepatitis B and hepatitis C virus infections in pregnant women in Sana'a, Yemen," BMC Pregnancy and Childbirth, vol. 13, article 127, 2013.

[31] T. M. Abdallah, M. H. Mohamed, and A. A. Ali, "Seroprevalence and epidemiological factors of hepatitis B virus (HBV) infection in Eastern Sudan," International Journal of Medicine and Medical Sciences, vol. 3, no. 7, pp. 239-241, 2011.

[32] M. Motazakker, M. S. Nagadeh, F. Khalili et al., "Hepatitis $B$ virus infection among pregnant women attending health care centers of Urmia," Journal of Guilan University of Medical Sciences, vol. 23, no. 89, pp. 45-50, 2014.

[33] C. E. Onwuakor, V. C. Eze, I. U. Nwankwo, and J. O. Iwu, "Seroprevalence of hepatitis B surface antigen (HBsAg) amongst pregnant women attending antenatal clinic at the Federal Medical Centre Umuahia, Abia State, Nigeria," American Journal of Public Health Research, vol. 2, no. 6, pp. 255-259, 2014.

[34] A. C. Eke, U. A. Eke, C. I. Okafor, I. U. Ezebialu, and C. Ogbuagu, "Prevalence, correlates and pattern of hepatitis B surface antigen in a low resource setting," Virology Journal, vol. 8, article 12, 2011.

[35] V. U. Usanga, L. Abia-Bassey, P. C. Inyang-Etoh, S. M. Udoh, F. Ani, and E. Archibong, "Prevalence of sexually transmitted diseases in pregnant and non-pregnant women in Calabar, cross river state, Nigeria," The Internet Journal of Gynecology and Obstetrics, vol. 14, no. 2, pp. 1-7, 2009.

[36] G. Fisseha, "Young women sexual behaviour and self-reported sexually transmitted diseases in northern ethiopia: a cross sectional study," European Journal of Preventive Medicine, vol. 3, no. 3, pp. 55-62, 2015.

[37] J. O. Alegbeleye, T. K. Nyengidik, and J. I. Ikimal, "Maternal and neonatal seroprevalence of hepatitis B surface antigen in a hospital based population in South-South, Nigeria," International Journal of Medicine and Medical Sciences, vol. 5, no. 5, pp. 241246, 2013.

[38] G. R. Pennap, E. T. Osanga, and A. Ubam, "Seroprevalence of hepatitis B surface antigen among pregnant women attending antenatal clinic in federal medical center Keffi, Nigeria," Research Journal of Medical Sciences, vol. 5, no. 2, pp. 80-82, 2011. 


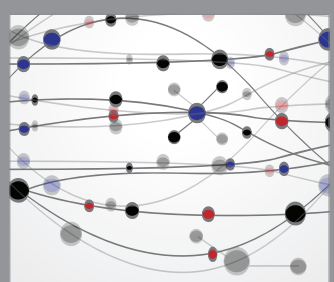

The Scientific World Journal
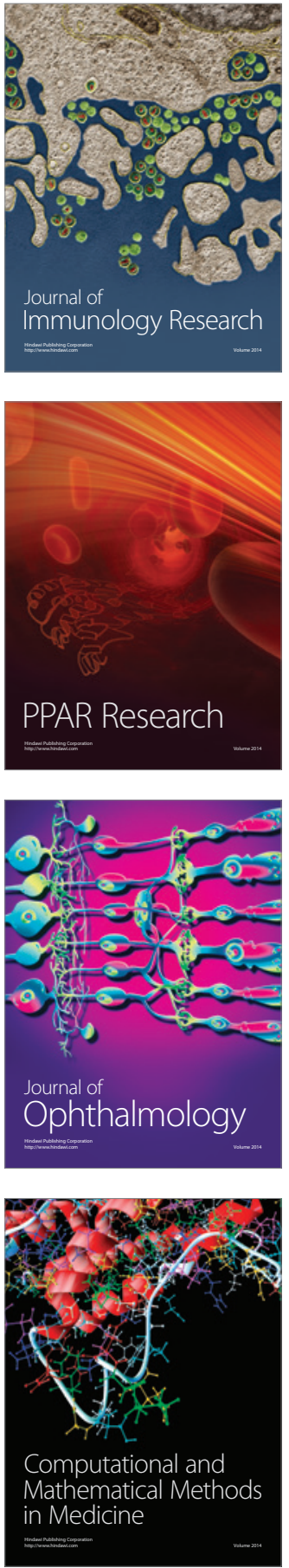

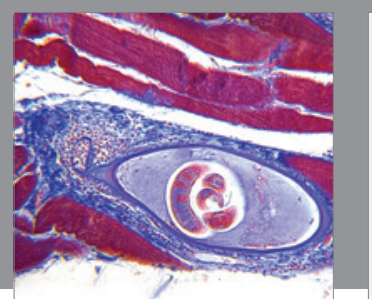

Gastroenterology Research and Practice

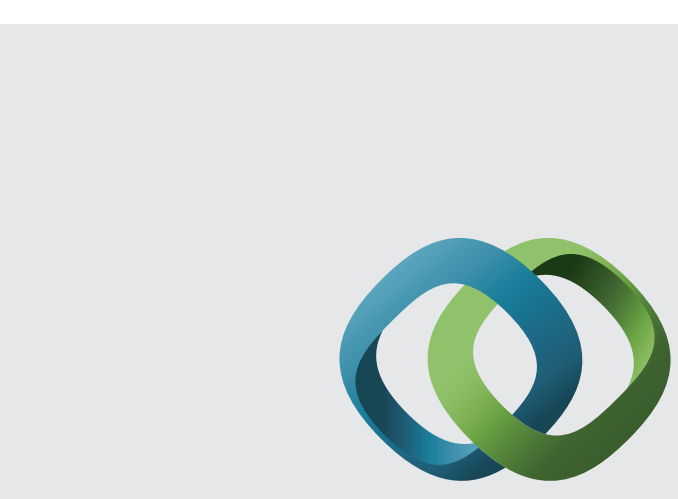

\section{Hindawi}

Submit your manuscripts at

http://www.hindawi.com
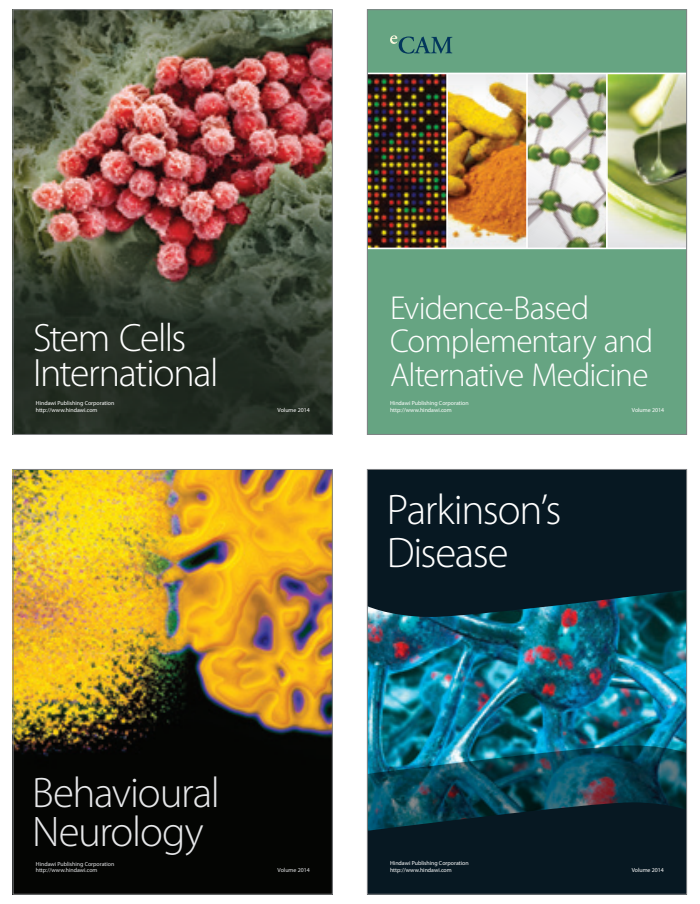
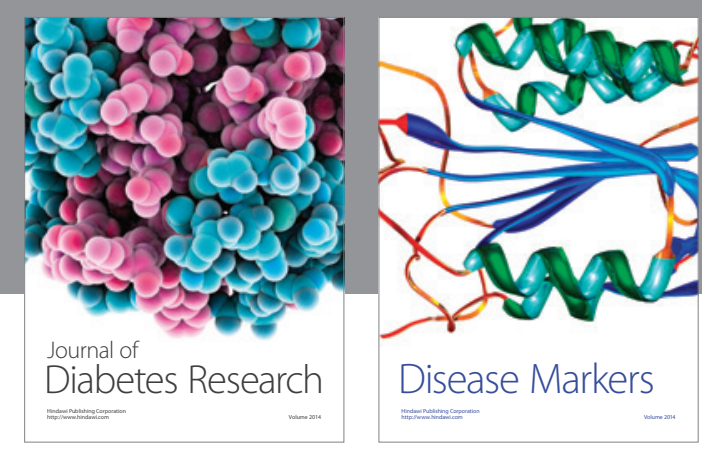

Disease Markers
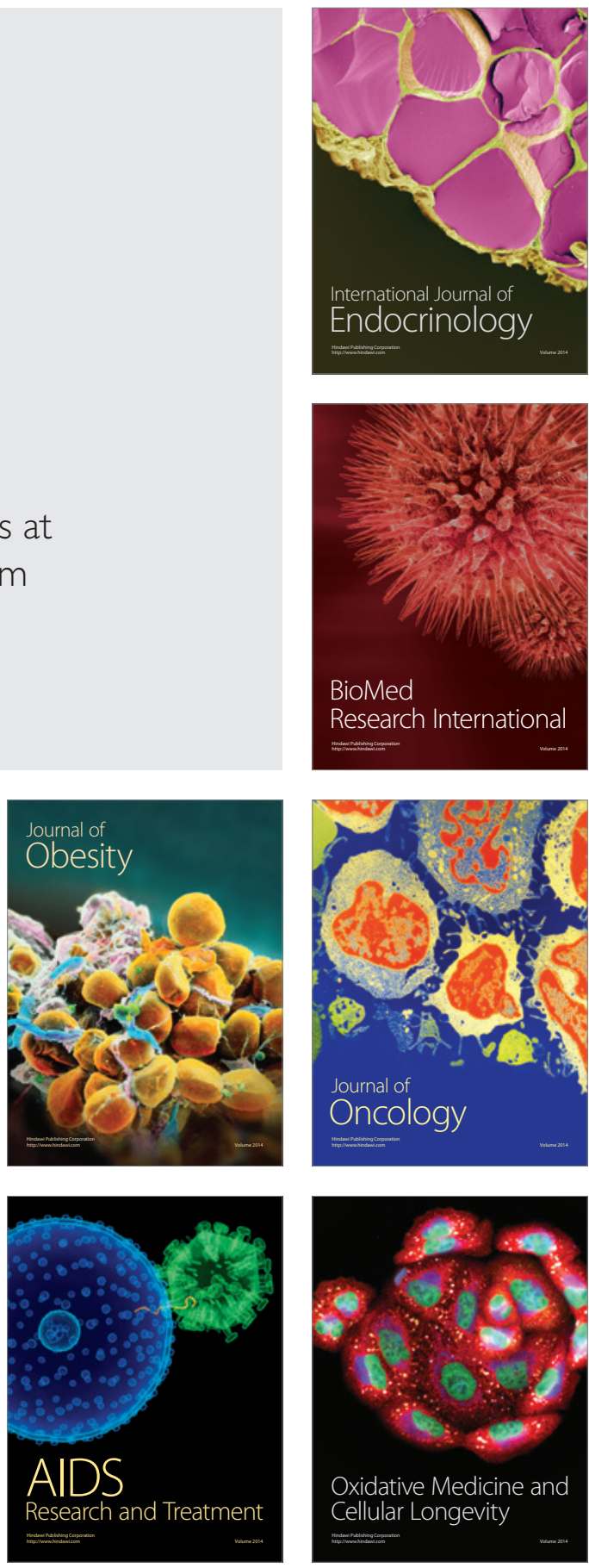